\title{
PELATIHAN MEKANIK SEPEDA MOTOR UNTUK ANAK PUTUS SEKOLAH DI KELURAHAN LABUHBARU BARAT, PAYUNG SEKAKI, PEKANBARU
}

\author{
Jusnita, Indra Hasan, Fikry Hadi \\ Prodi Teknik Otomotif, Fakultas Teknik \\ Universitas Muhammadiyah Riau \\ email: jusnita@umri.ac.id
}

\begin{abstract}
Needs service for motorcycles become a routine need to be done by users. The purpose of this activity is to provide training courses for workshop and training of automotive mechanics and to grow the entrepreneurship spirit, helping government program in overcoming unemployment. The methods used are lectures, questions, discussions, demonstrations and practice exercises. The benefits of this service are; The participants get the knowledge and mechanical skills otmotif, Lecturer can implement one tri Dharma Higher Education, for the local government the formation of qualified candidates. This activity was held in West Labuhbaru Village, Payung Sekaki Sub-district, followed by 15 participants, 1 elementary school graduate, 7 junior high school graduates and 7 senior high school graduates. This activity begins by gathering participants in the West Labuhbaru Village hall as a training ground. The results of community service activities in outline include the following components; 1). The success of the target number of trainees. 2) Achievement of training objectives 3) Achievement of material targets that have been planned 4). The ability of participants in the mastery of the material. Target trainees as planned before 10 people. In the implementation, this activity was attended by 15 participants. Thus it can be said that the target participants reached $100 \%$. The figures indicate that the community service activities seen from the number of participants who follow can be said successful / successful.
\end{abstract}

Keywords: Training, Workshop, Training, Automotive, Entrepreneurship

\begin{abstract}
Abstrak
Kebutuhan service bagi sepeda motor menjadi kebutuhan rutin yang harus dilakukan oleh penggunanya. Tujuan dari kegiatan ini adalah memberikan pelatihan program bengkel dan training mekanik otomotif dan menumbuh kembangkan jiwa kewirausahaan, membantu program pemerintah dalam mengatasi pengangguran. Metode yang digunakan adalah ceramah, Tanya jawab, diskusi, demonstrasi dan latihan praktek. Manfaat pengbdian ini adalah; Peserta pelatihan mendapatkan pengetahuan dan keterampilan mekanik otmotif, Dosen dapat melaksanakan salah satu tri darma Perguruan Tinggi, untuk pemerintah setempat terbentuknya calon tenaga kerja yang berkualitas. Kegiatan ini diadakan di Kelurahan Labuhbaru Barat Kecamatan Payung Sekaki, diikuti oleh 15 orang peserta, 1 orang tamatan SD, 7 orang tamatan SMP dan 7 orang tamatan SLTA. Kegiatan ini diawali dengan mengumpulkan peserta di aula Kelurahan Labuhbaru Barat sebagai tempat pelatihan. Hasil kegiatan pengabdian masyarakat secara garis besar mencakup beberapa komponen sebagai berikut; 1). Keberhasilan target jumlah peserta pelatihan. 2) Ketercapaian tujuan pelatihan 3)Ketercapaian target materi yang telah direncanakan 4). Kemampuan peserta dalam penguasaan materi. Target peserta pelatihan seperti direncanakan sebelumnya 10 orang. Dalam pelaksanaannya, kegiatan ini diikuti oleh 15 orang peserta. Dengan demikian dapat dikatakan bahwa target peserta tercapai 100\%. Angka tersebut menunjukkan bahwa kegiatan
\end{abstract}


pengabdian masyarakat dilihat dari jumlah peserta yang mengikuti dapat dikatakan berhasil/ sukses.

Kata kunci : Pelatihan, Bengkel, Training, Otomotif, Kewirausahan

\section{PENDAHULUAN}

Data dinas sosial Kota Pekanbaru menunjukkan anak putus sekolah masih terbilang tinggi, yakni mencapai 1.293 orang tersebar dari 12 kecamatan kota Pekanbaru. Jumlah anak putus sekolah berdasarkan data tahun 2014 mengindikasikan banyak masalah dalam dunia pendidikan, seperti diusia Sekolah Dasar (SD) dan Sekolah menengah Pertama (SMP), salah satu faktornya diakibatkan terbentur pada masalah biaya pendidikan, terutama untuk meneruskan studi kejenjang yang lebih tinggi membutuhkan biaya yang mahal.

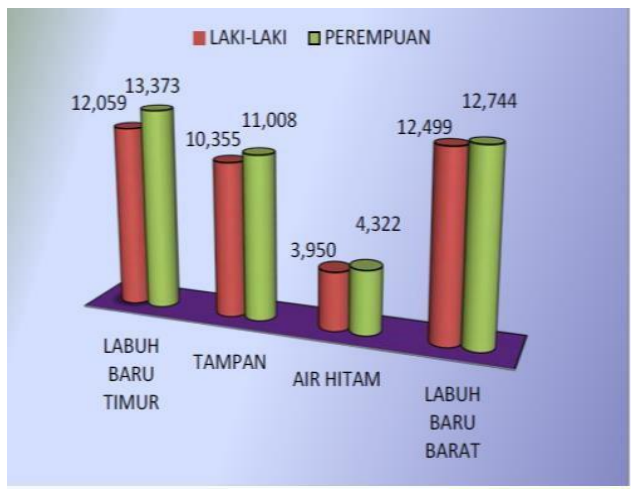

Gambar 1 Perbandingan Jumlah Penduduk Ka.Bid. Pelayanan \& Pemberdayaan Dinas Sosial

Pekanbaru mengatakan daerah kecamatan yang paling banyak anak putus sekolah adalah Kecamatan Payung Sekaki di Kelurahan Labuh Baru Barat berjumlah 251 orang dan 240 orang di Kecamatan Tenayan, 31 orang di Kecamatan Lima Puluh. Masalah yang dihadapi oleh Kelurahan Labuhbaru Barat Pekanbaru khususnya di RT 01 / RW 11 dan RT 03 / RW 14 Kecamatan Payung Sekaki adalah anak-anak yang tidak mampu melanjutkan pendidikan yang disebabkan salah satunya karena kondisi ekonomi keluarga yang memprihatinkan.

\begin{tabular}{|c|c|c|c|c|c|}
\hline \multirow[b]{2}{*}{ KELURAHAN } & \multicolumn{5}{|c|}{ TINGKAT PENDIDIKAN YANG DITAMATKAN } \\
\hline & $\begin{array}{l}\text { TIDAK/ } \\
\text { BELUM } \\
\text { PERNAH } \\
\text { SEKOLAH }\end{array}$ & $\begin{array}{l}\text { TIDAK/BELUM } \\
\text { TAMAT SD }\end{array}$ & SD & SLTP & SLTA \\
\hline (1) & (2) & (3) & (4) & (5) & (6) \\
\hline LABUH BARU TIMUR & 1,344 & 2,810 & 6,160 & 4,774 & 4,154 \\
\hline TAMPAN & 1,339 & 1,962 & 2,136 & 4,433 & 4,631 \\
\hline AIR HITAM & 422 & 911 & 1,007 & 1,601 & 1,489 \\
\hline LABUH BARU BARAT & 1,523 & 1,656 & 1,774 & 5,571 & 4,233 \\
\hline JUMLAH & 4,628 & 7,339 & 11,077 & 16,379 & 14,507 \\
\hline
\end{tabular}

Disadari bahwa kondisi ekonomi seperti ini menjadi penghambat bagi anak putus sekolah untuk melanjutkan pendidikan. Kondisi ini disebabkan berbagai faktor diantaranya; a) Orang tua berpendidikan rendah, b) Tidak mempunyai pekerjaan tetap, c) Tidak mempunyai keterampilan khusus dan keterbatasan dalam modal usaha dan faktor lainnya.

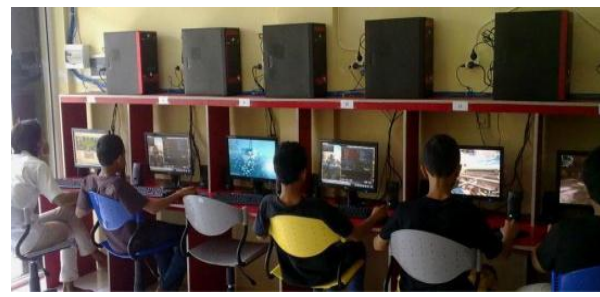

Gambar 2. Anak-anak putus sekolah yang bermain di warnet

Hal ini menyebabkan orang tua tidak sanggup membiayai pendidikan anaknya kejenjang pendidikan selanjutnya.

\section{METODE PENGABDIAN}

1. Metode Pelatihan 
Metode yang digunakan dalam pelatihan mekanik sepeda motor adalah:

2. Metode Ceramah Dan Tanya Jawab

Metode ini untuk menyajikan teori secara umum. Teori yang disampaikan adalah engine sepeda motor, pengenalan alat dan penggunaannya, dan keselamatan kerja. Penyajian materi pada metode ini menggunakan alat peraga langsung.

a. Metode Resitasi Dan Diskusi

Setelah tim pelaksana selesai menyajikan materi, tugas diberikan kepada peserta dalam bentuk modul pelatihan. Semua peserta membaca masing-masing modul yang telah disiapkan oleh tim

b. Metode Demonstrasi

Metoda demonstrasi merupakan sistem penyajian sub kerja pelayanan sepeda motor dengan teknis memperagakan kepada peserta. Sub kerja pelayanan sepeda motor terdiri dari:

1) Overhaul Engine;

2) Memperagakan suatu tindakan mencari gangguan kerusakan total pada mesin disaat mesin dikatagorikan rusak parah.

3) Service berkala dan perawatan;

4) Memperagakan suatu tindakan perbaikan yang dilakukan secara berkala dan intensif yang disesuaikan standar operasional produk (S.O.P)

3. Metoda Pratikum

Para peserta yang sudah dilengkapi dengan modul, langsung melakukan praktek dibawah bimbingan instruktur.

Metode demontrasi dan peragaan ini sangat efektif untuk pelatihan mekanik sepeda motor, peserta pelatihan menerapkan modul yang telah didiskusikan dengan tim pelaksana, secara langsung pada sepeda motor yang telah disiapkan.

\section{HASIL DAN PEMBAHASAN}

Hasil yang dicapai melalui kegiatan pengabdian ini dituangkan dalam bentuk hasil kegiatan pada setiap tahap pelaksanaan sebagai berikut;1) Perencanan 2) Pendaftaran 3) Penyusunan Program Pelatihan sepeda motor di Kelurahan Labuhbaru didomain pada tingkat sekolah menengah pertama (SMP), dan kedua pada tingkatan pendidikan Sekolah Menengah Kejuruan (SMK) serta yang ketiga adalah tingkat pendidikan sekolah dasar (SD).

Tabel 2. Tingkat Pendidikan dan Umur Peserta Pelatihan

\begin{tabular}{cc}
\hline Tingkat Pendidikan & Umur (tahun) \\
\hline SD & 17 \\
SMP & 20 \\
SMP & 15 \\
SMP & 16 \\
SMP & 17 \\
SMP & 20 \\
SMP & 15 \\
SMP & 15 \\
SMK & 21 \\
SMK & 16 \\
SMA & 23 \\
SMA & 17 \\
SMA & 16 \\
\hline
\end{tabular}

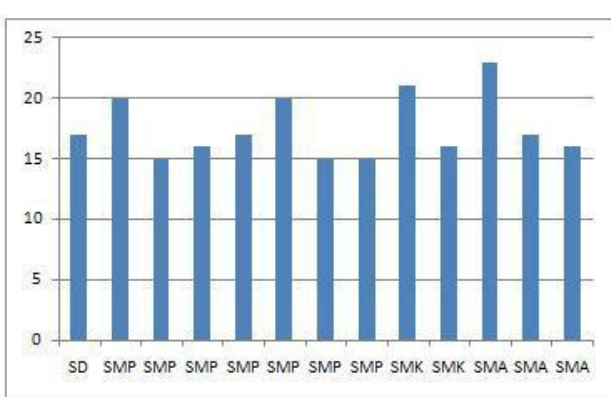

Gambar 3, Tingkat Pendidikan vs Umur

Jika dilihat dari tingkat umur ratarata menunjukan umur 15 sampai dengan 20 tahun. Hal ini menunjukan bahwa tingkat pendidikan di daerah Labuhbaru Barat Kecamatan Payung Sekaki bila dilihat dari data formulir pendaftaran peserta pelatihan, maka bisa dikatakan bahwa tingkat pendidikan didaerah tersebut masih rendah.

Setelah pelaksanaan kegiatan Program Kemitraa Masyarakat 
dilaksanakan, maka dilakukan evaluasi yang bertujuan untuk;

1. Sejauh mana penyerapan materi dari peserta pelatihan Mekanik Sepeda Motor

2. Mengetahui kemampuan masing masing peserta pelatihan Mekanik Sepeda motor dengan uji kompetensi

3. Mengelola waktu/memanage pelatihan Mekanik Sepeda Motor dengan baik.

Respon peserta pelatihan akan diukur melalui observasi selama pelatihan berlangsung dengan mengdakan diskusi yang menyangkut kesan, saran, kritik dan usulan peserta pelatihan terhadap Program Kemitraan Masyarakat (PKM). Keterampilan peserta akan diobservasi saat pelatihan melakukan tes awal dan akhir tentang perbaikan dan perawatan sepeda motor

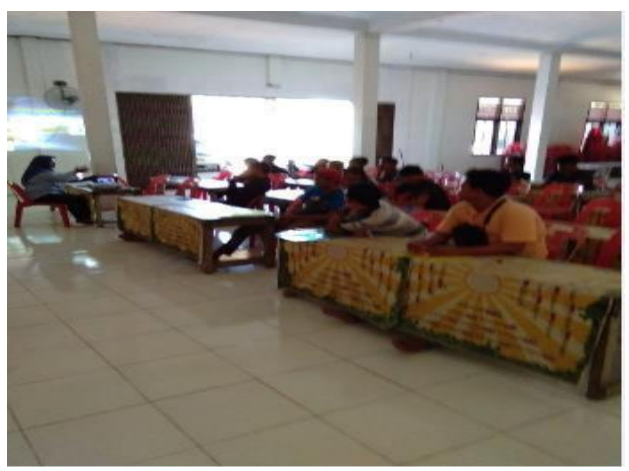

Gambar 4 Materi Keselamatan Kerja

Tujuan akhir dari kegiatan pelatihan ini adalah memberikan pengetahuan dan pemahamam dari mekanik sepeda motor seperti memperbaiki, merawat, dan mendiagnosa kerusakan sepeda motor. Penilaian keberhasilan dari kegiatan ini dapat dilihat melalui kemajuan pengetahuan dan pemahamam serta keterampilan melalui perbandingan antara tes teori dan tes praktek dan juga keterampilan peserta dalam mendiagnosa kerusakan sepeda motor melalui observasi.
Tabel 3 Hasil Evaluasi Peserta Pelatihan

\begin{tabular}{lcccc}
\hline \multicolumn{1}{c}{$\begin{array}{c}\text { Nama } \\
\text { Peserta }\end{array}$} & $\begin{array}{c}\text { Tingkat } \\
\text { Pendidikan }\end{array}$ & $\begin{array}{c}\text { Tes } \\
\text { Awal }\end{array}$ & $\begin{array}{c}\text { Tes } \\
\text { Akhir }\end{array}$ & $\begin{array}{c}\text { Observasi } \\
\text { Praktek }\end{array}$ \\
\hline Solihin Baktiar & SMK & 70 & 85 & 85 \\
Agus Prasetiawan & SMK & 75 & 90 & 90 \\
Fadly Al Khair & SMA & 70 & 80 & 85 \\
Supriyadi & SMA & 70 & 90 & 85 \\
Aldi Irfan Windra & SMA & 65 & 80 & 85 \\
Guntur Ramadona Putra & SMP & 60 & 85 & 85 \\
Reza Ramadhan & SMP & 50 & 75 & 85 \\
Riandi & SMP & 50 & 75 & 85 \\
M. Rozi & SMP & 55 & 75 & 80 \\
Dani Saputra & SMP & 50 & 80 & 90 \\
M. Fauzi & SMP & 45 & 70 & 85 \\
Yahya Al Khair & SMP & 45 & 75 & 85 \\
Junaidi & SD & 45 & 70 & 85 \\
\hline
\end{tabular}

Berdasar hasil evaluasi hasil tes awal, akhir dan observasi praktek sebagaimana yang terdapat pada tabel 2. seluruh peserta (100\%) nilainya mengalami peningkatan. Dilihat dari tes akhir seluruh peserta mendapatkan nilai rata-rata diatas 75 (nilai KKM). Jadi dapat diambil disimpul bahwa pelatihan mekanik sepeda motor untuk anak putus sekolah berhasil sesuai yang diharap.

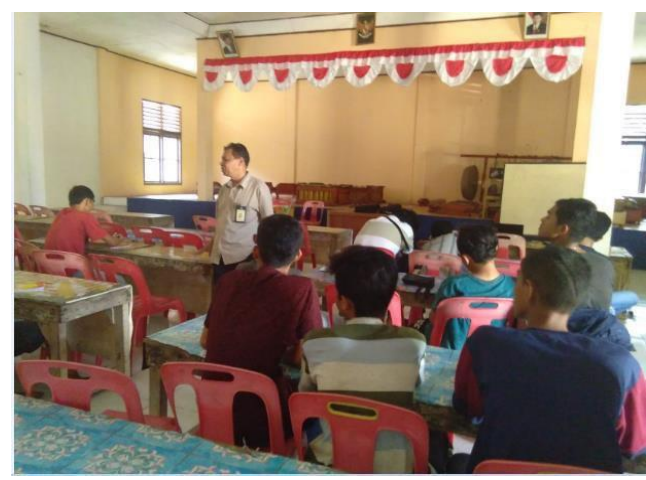

Gambar 5. Materi Teori

Meningkatkan pengetahuaan dan keterampilan pemuda dilingkungan Kelurahan Labuhbaru Barat Kecamatan Payung Sekaki, kegiatan ini dilakukan melalui pemberian pelatihan program kemitraan masyarakat yang sesuai dengan Standar Operasional Prosedur (SOP). Pemberian materi pelatihan teori di bimbingan oleh tim pelaksana (dosen Program Studi Mesin Otomotif Fakultas Teknik UMRI) dengan memberi modul kepada peserta pelatihan. 


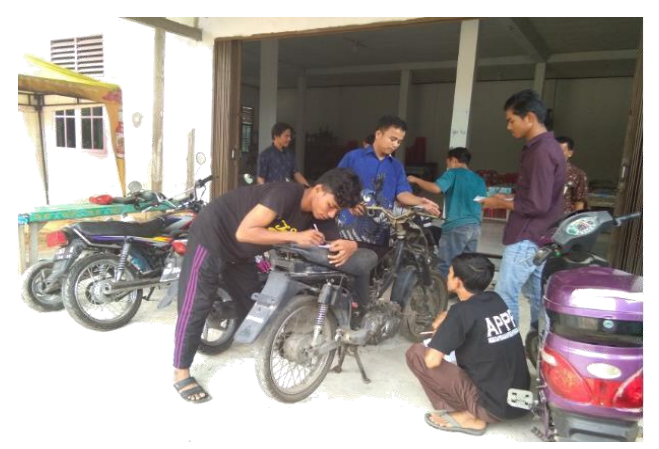

Gambar 6. Materi Praktek

\section{KESIMPULAN}

Hasil yang dicapai melalui kegiatan program pengabdian masyarakat ini untuk pemuda di Kelurahan Labuhbaru Barat adalah (1) Menambah ilmu pengetahuan dan keterampilan tentang mekanik otomotif dengan pendekatan IPTEK terapan, mengalami peningkatan dari kategori kurang menjadi baik; (2) Rata-rata kemampuan peserta pelatihan menggunakan media pembelajaran mekanik otomotif yang telah dikembangkan sehingga berkualitas baik; (3)Terbukanya peluang-peluang usaha bengkel untuk pemuda di Kelurahan Labuhbaru Barat Kecamatan Payung Sekaki; (4) Dapat membantu pemerintah dalam mengatasi penganguran

\section{UCAPAN TERIMAKASIH}

Ucapan terima kasih atas pelaksanaan kegiatan pengabdian masyarakat kepada :

1. Kemenristek Dikti Penelitian dan Pengabdian Masyarakat

2. Rektor Universitas Muhammadiyah Riau yang telah menfasilitasi kegiatan pengabdian masyarakat ini.

3. Ketua LPPM UMRI yang telah mengagendakan kegiatan pengabdian masyarakat di lingkunan dosen UMRI.

4. Dekan Fakultas Teknik UMRI yang telah member dukungan atas pelaksaan pengabdian ini.Ketua Program Studi Mesin Otomotif yang telah memotifasi kegiatan pengabdian ini.

5. Semua dosen dan mahasiswa Program Studi Mesin Otomotif yang terlibat dalam agenda pengabdian masyarakat ini.

\section{DAFTAR PUSTAKA}

1. Badan Pusat Statistik Kota Pekanbaru, (2010). Kecamatan Payung Sekaki Dalam Angka.http://www.riau24.com

2. Badan Pusat Statistik Kota Pekanbaru, (2014). Kecamatan Payung Sekaki Dalam Angka.http://www.riau24.com

3. Buku panduan reparasi Honda beat, technical service divison TSR10 PR $002 \quad 82$ KYTHO, Bi.Mal.A 5000.2010.08.10 Yamaha Motor Co.Ltd Service Advision, Basic Mechanic Training (BMT) 9089400108, Otomotifnet.com

4. Nugroho Beni Satriya, Sriyanto Joko, 2007, Aplikasi Teknologi Injeksi Bahan Bakar Elektronik (EFI) untuk Mengurangi Emisi Gas Buang Sepeda Motor

5. Suzuki Indonenesia.,(2012)., Mesin Hemat Bahan Bakar dengan Service Berkala., Book Manual Service.,vol 2.,hal 23-24 UNEP., (2008).,Pedoman Efisiensi Energi untuk Industri di Asia-www.Energy efficiency asia.org.

6. Astra Motor,2012, Buku Pedoman Reparasi Honda Baet. Jakarta : PT.Astra Motor

7. Urip, sudirman, 2011. Bikin irit speda motor matik, Bandung: Penerbit Tri Niti Masa

8. Soedarmo, Hartoto. 2008. Praktek merawat dan memperbaiki sepeda motor. Jakarta : Gramedia pustaka utama 